Universidade Tecnológica Federal do Paraná - UTFPR

Campus Ponta Grossa - Paraná - Brasil

ISSN: $1981-3686 /$ v. 05, n. 02: p. 531-541, 2011

D.O.I.: $10.3895 / \mathrm{S} 1981-36862011000200005$
Revista Brasileira de Tecnologia

Agroindustrial

\title{
ANÁLISE E CONTROLE DE SOBRAS DE ALIMENTOS EM UMA EMPRESA FORNECEDORA DE REFEIÇÕES TRANSPORTADAS NO MUNICÍPIO DE CHAPECO - SC
}

\section{ANALYSIS AND CONTROL OF FEED REMAINS IN A COMPANY PROVIDING MEALS BROUGHT IN THE CITY OF CHAPECO - SC}

\author{
Aline Vargas ${ }^{1}$; Tiffany Prokopp Hautrive ${ }^{2}$; \\ ${ }^{1,2}$ Universidade Comunitária da Região de Chapecó - UNOCHAPECÓ - Chapecó - Brasil \\ aline.vargas@ hotmail.com \\ ${ }^{2}$ Universidade Federal de Santa Maria - UFSM - Santa Maria - Brasil tiffanyhautrive@yahoo.com.br
}

\begin{abstract}
Resumo
Uma das condições primordiais ao bom desempenho das Unidades de Alimentação e Nutrição é o planejamento adequado do volume de refeições preparadas, pois este visa entre outros aspectos diminuir ou controlar excessos de produção e consequentes sobras. O presente trabalho se propôs analisar e controlar as sobras de alimentos em uma empresa fornecedora de refeições transportadas no município de Chapecó - SC. O estudo foi realizado em seis pólos que recebem as refeições transportadas. Para obter o valor de sobras, foram pesadas as cubas com as preparações enviadas aos locais, bem como as sobras de Hot Box e sobras do bufê. Os resultados apresentaram-se positivos, já que no inicio do trabalho em média 16,6\% das quantidades enviadas eram sobras; ao final do ajuste das quantidades enviadas, às sobras foram de 3,63\%. As quantidades foram ajustadas gradativamente, através do contato com os pólos, orientação aos cozinheiros quanto ao porcionamento, além de visitas semanais aos pólos identificando as particularidades de cada local. Verificou-se que a padronização dos processos de serviços, orientação a equipe e o monitoramento constante das atividades desenvolvidas tornaram possível a diminuição das sobras nos seis pólos receptores de refeições transportadas estudados.
\end{abstract}

Palavras-chave: serviços de alimentação; alimentação coletiva; refeições transportadas; desperdício de Alimentos; capacitação em serviço

\section{Introdução}

As Unidades de Alimentação e Nutrição (UAN) são estabelecimentos que trabalham com produção e distribuição de alimentos para coletividade (ABREU et al., 2003).

Segundo Teixeira et al. (2004) e Kawasaki et al. (2007) o foco de uma UAN é fornecer uma alimentação com qualidade nutricional, segura e que seja adequada ao comensal, já que as mesmas desempenham importante papel em termos de economia e saúde pública, na medida em 
que afetam o estado de saúde e o bem-estar da população por meio da qualidade do alimento que produzem.

As UAN podem apresentar diferentes modalidades de serviço, destacam-se entre essas, o sistema de refeições transportadas, a qual permite o fornecimento de refeições onde não há estrutura apropriada para sua produção. A distribuição pode ser efetuada individualmente, através de marmitex ou em cubas de bufês. Embora não haja muitos estudos sobre esse tipo de segmento do mercado, observa-se o referido sistema torna-se uma realidade nacional, utilizado tanto nos grandes centros urbanos como em locais afastados e de difícil acesso (BAZANELLA e MARTINS, 2008).

Uma das condições primordiais ao bom desempenho dos Serviços de Alimentação é o planejamento adequado do volume de refeições a ser preparado, pois este visa entre outros aspectos diminuir ou controlar o desperdício de alimentos (SILVA JUNIOR e TEIXEIRA, 2008).

No Brasil, jogam-se no lixo 39 mil toneladas de alimentos por dia. Isso faz do país o líder mundial em desperdício de alimentos. Segundo a Organização das Nações Unidas para Agricultura e Alimentação (FAO) dos 43,8 milhões de toneladas de lixo gerados pelo Brasil anualmente, 26,3 milhões de toneladas são de alimentos (COTRIM e SACCOMANI, 2008).

A cultura do desperdício se incorporou de tal forma à vida brasileira que nada de concreto é feito para reverter os números absurdos do que se perde, que fizeram do País o campeão mundial de desperdício. Segundo dados da Organização das Nações Unidas, o Brasil manda para o lixo 30\% de tudo que produz, isto é, 160 bilhões de dólares por ano, que poderiam aliviar a fome de mais de oito milhões de famílias. Num país onde mais de 30 milhões de pessoas estão abaixo da linha da pobreza, desperdiçar é acima de tudo antiético e um desrespeito à cidadania (INSTITUTO ETHOS, 2010)

Em uma empresa fornecedora de alimentos, o desperdício é proveniente da sobra de alimentos, ou seja, alimentos preparados e não distribuídos, ou restos, alimentos distribuídos e não consumidos (TEIXEIRA et al., 2004).

Uma das principais causas da superprodução é o medo de que faltem refeições. Por força da legislação sanitária vigente, os alimentos não consumidos (sobra) são eliminados (SANTOS e LANZILLOTTI, 2008).

Para Abreu et al. (2003) o desperdício de alimentos em uma UAN pode ser evitado por meio de um planejamento e monitoramento adequado, a fim de que não existam excessos de produção e conseqüentes sobras.

Como ferramenta para minimizar a quantidade de desperdício de alimentos as unidades vem buscando identificar as particularidades e hábitos alimentares do público atendido e assim definir a quantidades de consumo através do per capita de cada alimento (CASTRO, 2003). 
Entre as diversas metodologias existentes para determinar o consumo alimentar médio, a pesagem direta é a mais utilizada, sensível e confiável. Apesar deste método, demandar mais tempo na coleta dos dados, com ele se obtém valores necessários ao planejamento, à organização, ao controle e à avaliação, tanto dos processos operacionais da UAN, quanto da adequação nutricional da refeição servida (AMORIM e JUNQUEIRA, 2005).

Outro aspecto a ser considerado ao se tratar de desperdício de alimentos, refere-se ao treinamento dos colaboradores, já que segundo Teixeira et al. (2004) o treinamento proporciona informações aos empregados sobre as técnicas dietéticas, visando diminuir e /ou evitar o desperdício de gêneros alimentícios e resultados danosos ao valor nutritivo das refeições. O mesmo deve acontecer de forma agradável e dinâmica fazendo com que o empregado entenda o motivo de trabalhar de forma correta (ABREU et al., 2003).

Com base nisso, o presente estudo se propõe a analisar e controlar as sobras de alimentos em uma empresa fornecedora de refeições transportadas no município de Chapecó - SC.

\section{Material e Métodos}

O presente estudo foi realizado em uma unidade fornecedora de refeições transportadas, que oferece refeições a seis pólos diferentes, representados neste estudo pelas letras A, B, C, D, E, e F.

\section{Verificação das quantidades de alimentos enviadas aos pólos}

Durante 05 dias consecutivos foram pesadas as cubas com as preparações enviadas aos locais, em balança analógica de marca Toledo com capacidade máxima de $250 \mathrm{Kg}$, sendo que o peso da cuba foi descontado. Posteriormente, as cubas foram colocadas nos Hot Box (caixas térmicas), e destinadas aos pólos correspondentes.

\section{Verificação das sobras de alimentos}

No estudo, foram classificadas como sobras os alimentos presentes nos Hot Box, que mesmo não sendo expostas no bufê, foram descartadas devido ao processo de distribuição transportada; além das sobras presentes no bufê ao final da distribuição nos pólos.

Durante os mesmos 05 dias, verificou-se o peso das sobras (sobra Hot Box + sobra de bufê) da seguinte forma:

Sobra Hot Box: assim que os Hot Box retornavam a unidade, eram verificadas as quantidades de sobras nas cubas, as mesmas eram pesadas em balança digital, marca Filizola, capacidade de $15 \mathrm{~kg}$, descontando o peso da cuba. A balança analógica da marca Toledo foi 
substituída pela balança Filizola, devido à flexibilidade de deslocamento até a área suja, porém ambas apresentavam-se calibradas.

Sobra de bufê: A verificação das sobras de bufê aconteceu através do contato com o responsável das copas de cada pólo. Os mesmos foram orientados a realizar a pesagem das sobras em medidas caseiras ou unidades (concha para feijão, e sopas, unidade para alimentos secos e escumadeira para as demais preparações), já que os locais não apresentam balança. As medidas caseiras foram transformadas em gramas e somadas juntamente com as sobras do Hot Box, obtendo assim o total de sobras de cada pólo.

\section{Ajustes das quantidades de alimentos enviadas aos pólos}

Após avaliação das sobras presentes nos Hot Box e bufês, iniciou-se o processo de ajuste das preparações.

Inicialmente foram repassadas orientações às cozinheiras responsáveis pelo porcionamento das cubas na unidade fornecedora, quanto à pesagem das quantidades enviadas e a importância das mesmas para a efetivação do trabalho.

Para as preparações diárias (arroz, feijão e pão) estabeleceu-se uma média dos valores do consumo inicial de cada pólo, sendo os valores ainda ajustados durante o período, quando necessário.

O ajuste das carnes foi realizado apenas com as carnes em molho (frango e salsicha), devido a estas preparações apresentarem maiores valores de sobras. Quanto aos acompanhamentos, foram selecionados o ajuste das massas, polenta e purê de batata.

Para as saladas estabeleceu-se uma média entre as saladas folhosas (alface, alface americana, chicória, almeirão, radiche, acelga, mista verde, repolho, couve) e demais saladas (tomate, nabo, rabanete, pepino, tabule, vinagrete, cenoura e beterraba ralada). As sobremesas foram ajustadas conforme número de refeições, já que são servidas por unidade.

Para as preparações que não se apresentavam diariamente no cardápio, ajustou-se os valores enviados a partir da primeira quantidade destinada e suas sobras.

As quantidades foram ajustadas gradativamente, através do contato com os pólos, quanto ao número de refeições e à quantidade de sobras, além de visitas semanais que possibilitaram uma visão ampliada das particularidades de cada local e verificação da real necessidade.

Foi realizado um comparativo entre as sobras antes e depois dos ajustes, verificando assim a eficácia do trabalho realizado.

Os valores enviados aos pólos, bem como as sobras (sobra Hot Box + sobra bufê) foram preenchidos em planilha de controle de sobras. 


\section{Resultados e Discussão}

O público atendido com o presente trabalho compreendeu 273 comensais entre os seis pólos pesquisados. A estrutura do cardápio enviado foi composta por arroz, feijão, pão, carne 1, carne 2, acompanhamento, salada 1, salada 2, sobremesa e suco.

A tabela 1 demonstra a média de quantidades de arroz, feijão e pão enviadas aos pólos, juntamente com os valores de sobras sujas de cada preparação, antes das intervenções sugeridas.

Tabela 1 - Média de sobras de arroz e feijão antes das intervenções em uma unidade fornecedora de refeições transportadas, Chapecó- Santa Catarina

\begin{tabular}{cccccccc}
\hline \multicolumn{7}{c}{} & \multicolumn{2}{c}{ ARROZ } & $\begin{array}{c}\text { PREPARAÇÕES } \\
\text { FEIJÃo }\end{array}$ & \multicolumn{2}{c}{ PÃo } \\
\hline Pólos & $\begin{array}{c}\text { Número de } \\
\text { refeições }\end{array}$ & $\begin{array}{c}\text { Peso } \\
\text { enviado } \\
\mathbf{( k g )}\end{array}$ & Sobras (kg) & $\begin{array}{c}\text { Peso } \\
\text { enviado }\end{array}$ & Sobras (kg) & $\begin{array}{c}\text { Unidades } \\
\text { enviadas }\end{array}$ & $\begin{array}{c}\text { Sobras } \\
\text { (Unid) }\end{array}$ \\
\hline A & 20 & 8,000 & 2,500 & 7,400 & 1,800 & 40 & 5 \\
B & 100 & 18,000 & 0,420 & 13,500 & 0,360 & 180 & 22 \\
C & 20 & 5,300 & 1,260 & 7,100 & 4,060 & 40 & 9 \\
D & 60 & 16,000 & 0,840 & 16,200 & 2,880 & 120 & 2 \\
E & 45 & 11,750 & 3,220 & 9,500 & 0,960 & 90 & 8 \\
F & 28 & 6,000 & 1,960 & 7,600 & 3,120 & 60 & 13 \\
\hline Total & 273 & 65,050 & 10,200 & 61,300 & 13,180 & 530 & 59 \\
\hline
\end{tabular}

A tabela 2 apresenta a média das mesmas preparações ajustadas e enviadas ao final da pesquisa.

Tabela 2 - Média de sobras de arroz, feijão e pão após intervenções em uma unidade fornecedora de refeições transportadas, Chapecó - Santa Catarina

\begin{tabular}{|c|c|c|c|c|c|c|c|}
\hline \multirow[b]{3}{*}{ Pólos } & \multirow[b]{3}{*}{$\begin{array}{l}\text { Número de } \\
\text { refeições }\end{array}$} & \multicolumn{6}{|c|}{ PREPARAÇÕES } \\
\hline & & \multicolumn{2}{|c|}{ ARROZ } & \multicolumn{2}{|c|}{ FEIJÃO } & \multicolumn{2}{|c|}{ PÃO } \\
\hline & & $\begin{array}{c}\text { Peso } \\
\text { enviado } \\
(\mathbf{k g})\end{array}$ & Sobras (kg) & $\begin{array}{c}\text { Peso } \\
\text { enviado }\end{array}$ & Sobras (kg) & $\begin{array}{l}\text { Unidades } \\
\text { enviadas }\end{array}$ & $\begin{array}{l}\text { Sobras } \\
\text { (Unid) }\end{array}$ \\
\hline $\mathbf{A}$ & 20 & 3,300 & 0,420 & 2,500 & 0,000 & 30 & 1 \\
\hline B & 100 & 17,500 & 0,000 & 12,500 & 0,000 & 140 & 3 \\
\hline C & 20 & 3,000 & 0,000 & 2,500 & 0,240 & 28 & 2 \\
\hline D & 60 & 11,500 & 0,000 & 11,700 & 0,000 & 120 & 3 \\
\hline $\mathbf{E}$ & 45 & 8,000 & 0,000 & 6,000 & 0,360 & 60 & 5 \\
\hline $\mathbf{F}$ & 28 & 3,800 & 0,840 & 4,000 & 0,000 & 40 & 3 \\
\hline Total & 273 & 47,100 & 1,260 & 39,200 & 0,600 & 418 & 17 \\
\hline
\end{tabular}


Com relação aos valores demonstrados nas tabelas 1 e 2, observa-se uma redução significativa de sobras das três preparações. Ao analisar a média da quantidade enviada e das sobras de arroz, identificou-se valor inicial de 10,200 kg e após intervenção 1,260 kg do total enviado. Quanto ao feijão, a média de sobra inicial foi de $13,180 \mathrm{~kg}$, e após a intervenção $0,600 \mathrm{~kg}$. O pão apresentava inicialmente sobra de 59 unidades do valor enviado, com o ajuste, os valores passaram para 17 unidades.

Algumas medidas podem melhorar o controle de sobras como: planejamento correto do número de refeições e quantidades per capita, elaboração de cardápios que satisfaçam a população atendida, treinamento e conscientização da equipe para fazer as preparações em quantidades adequadas (VAZ, 2006).

As quantidades de carnes em molho e acompanhamentos enviadas aos pólos, antes e após intervenções, podem ser visualizadas nas tabelas 3 e 4 .

Tabela 3 - Média de sobras de carnes em molho e acompanhamentos, antes das intervenções em uma unidade fornecedora de refeições transportadas, Chapecó - Santa Catarina

\begin{tabular}{|c|c|c|c|c|c|}
\hline & & \multicolumn{4}{|c|}{ PREPARAÇÕES } \\
\hline & & \multicolumn{2}{|c|}{$\begin{array}{c}\text { CARNES EM MOLHO } \\
\text { (salsicha e frango em molho) }\end{array}$} & \multicolumn{2}{|c|}{$\begin{array}{c}\text { ACOMPANHAMENTOS } \\
\text { (Massa, polenta e purê de batata) }\end{array}$} \\
\hline Pólos & $\begin{array}{l}\text { Número de } \\
\text { refeições }\end{array}$ & $\begin{array}{l}\text { Peso enviado } \\
\text { (kg) }\end{array}$ & Sobras (kg) & Peso enviado (kg) & Sobras (kg) \\
\hline $\mathbf{A}$ & 20 & 7,000 & 2,500 & 13,500 & 1.36 \\
\hline B & 100 & 10,000 & 3,000 & 20,000 & 0,000 \\
\hline $\mathbf{C}$ & 20 & 7,500 & 4,900 & 9,500 & 0,340 \\
\hline D & 60 & 13,000 & 6,000 & 19,500 & 0,680 \\
\hline $\mathbf{E}$ & 45 & 10,000 & 6,600 & 16,000 & 1,190 \\
\hline $\mathbf{F}$ & 28 & 7,500 & 5,500 & 8,000 & 0,170 \\
\hline Total & 273 & 55,000 & 28,500 & 86,500 & 2,380 \\
\hline
\end{tabular}

Tabela 4 - Média de sobras de carnes em molho e acompanhamentos, após intervenções em uma unidade fornecedora de refeições transportadas, Chapecó - Santa Catarina

\begin{tabular}{|c|c|c|c|c|c|}
\hline \multirow[b]{3}{*}{ Pólos } & \multirow[b]{3}{*}{$\begin{array}{l}\text { Número de } \\
\text { refeições }\end{array}$} & \multicolumn{4}{|c|}{ PREPARAÇÕES } \\
\hline & & \multicolumn{2}{|c|}{$\begin{array}{l}\text { CARNES EM MOLHO } \\
\text { (salsicha e frango em molho) } \\
\end{array}$} & \multicolumn{2}{|c|}{$\begin{array}{l}\text { ACOMPANHAMENTO } \\
\text { (Massa, polenta e purê de batata) }\end{array}$} \\
\hline & & $\begin{array}{l}\text { Peso enviado } \\
\quad(\mathrm{kg})\end{array}$ & Sobras $(\mathbf{k g})$ & Peso enviado (kg) & Sobras $(\mathbf{k g})$ \\
\hline A & 20 & 2,000 & 0,000 & 7,500 & 0,000 \\
\hline B & 100 & 8,000 & 0,480 & 20,000 & 0,510 \\
\hline $\mathbf{C}$ & 20 & 2,000 & 0,360 & 7,500 & 0,000 \\
\hline D & 60 & 5,400 & 0,360 & 16,500 & 0,340 \\
\hline $\mathbf{E}$ & 45 & 3,200 & 0,000 & 12,600 & 0,340 \\
\hline $\mathbf{F}$ & 28 & 2,000 & 0,000 & 7,800 & 0,170 \\
\hline Total & 273 & 22,600 & 1,200 & 71,900 & 1,360 \\
\hline
\end{tabular}


Diante dos valores demonstrados nas tabelas 3 e 4 observa-se uma redução de ambas preparações. As carnes em molho apresentam baixa aceitação de consumo, sendo a preparação com valor mais significativo de redução, já que no início do estudo a média de sobras era de 28,500 kg, e após ajuste das quantidades enviadas, o valor passou para 1,200 kg.

Segundo Abreu et al. (2003) em uma UAN, a preferência alimentar é norteada pela quantidade de sobras das preparações. Segue-se a seguinte lógica: a preparação alimentar com maior quantidade de sobra é considerada de menor aceitação.

Ao analisar os acompanhamentos, identificou-se média de sobras sem intervenção de 2,380 $\mathrm{kg}$, sendo que após ajuste o índice de sobras passou para 1,360 Kg.

Com relação à média de sobras de saladas, os valores obtidos antes e após intervenção podem ser visualizados nas tabelas 5 e 6.

Tabela 5 - Média de sobras de saladas folhosas e demais saladas, antes das intervenções propostas, em uma unidade fornecedora de refeições transportadas. Chapecó, Santa Catarina, 2009

\begin{tabular}{|c|c|c|c|c|c|}
\hline & & \multicolumn{2}{|c|}{ FOLHOSOS } & \multicolumn{2}{|c|}{ DEMAIS SALADAS } \\
\hline Pólos & $\begin{array}{l}\text { Número de } \\
\text { refeições }\end{array}$ & $\begin{array}{c}\text { Peso enviado } \\
\text { (kg) }\end{array}$ & Sobras (kg) & $\begin{array}{l}\text { Peso enviado } \\
\text { (kg) }\end{array}$ & Sobras (kg) \\
\hline A & 20 & 3,200 & 1,600 & 3,204 & 1,600 \\
\hline B & 100 & 8,050 & 2,050 & 8,076 & 4,030 \\
\hline C & 20 & 3,670 & 2,440 & 2,660 & 1,330 \\
\hline D & 60 & 6,310 & 3,000 & 7,500 & 3,500 \\
\hline $\mathbf{E}$ & 45 & 4,130 & 1,370 & 4,090 & 2,000 \\
\hline $\mathbf{F}$ & 28 & 2,410 & 0,800 & 3,405 & 1,135 \\
\hline Total & 273 & 27,770 & 11,260 & 28,935 & 13,595 \\
\hline
\end{tabular}

Tabela 6 - Média de sobras de saladas, após intervenções em uma unidade fornecedora de refeições transportadas, Chapecó- Santa Catarina

\begin{tabular}{cccccc}
\hline Pólos & $\begin{array}{c}\text { Número de } \\
\text { refeições }\end{array}$ & $\begin{array}{c}\text { Peso enviado } \\
(\mathbf{k g})\end{array}$ & Sobras $(\mathbf{k g})$ & $\begin{array}{c}\text { Peso enviado } \\
(\mathbf{k g})\end{array}$ & Sobras (kg) \\
\hline $\mathbf{A}$ & 20 & 1,200 & 0,000 & 1,050 & 0,000 \\
$\mathbf{B}$ & 100 & 5,500 & 0,300 & 3,750 & 0,000 \\
$\mathbf{C}$ & 20 & 1,100 & 0,000 & 1,030 & 0,150 \\
$\mathbf{D}$ & 60 & 3,200 & 0,200 & 2,680 & 0,300 \\
$\mathbf{E}$ & 45 & 2,500 & 0,000 & 2,350 & 0,000 \\
$\mathbf{F}$ & 28 & 1,500 & 0,000 & 2,150 & 0,400 \\
\hline Total & 273 & 15,000 & 0,500 & 13,010 & 0,850 \\
\hline
\end{tabular}


Ao comparar os valores das tabelas 5 e 6, é possível visualizar valores positivos quanto a diminuição de sobras em ambas preparações. A média de sobras de saladas folhosas inicialmente era de 11,260 kg, sendo que após intervenções apresentou-se em 0,500 kg. Quanto às demais saladas, a média de sobras antes das intervenções era de 13,595 kg, e após passou para 0,850 kg.

Santos e Lanzillotti (2008) citam que as razões para a superprodução de alimentos podem ser explicadas por falhas no planejamento, trazendo como consequência per capita inadequados, excesso de produção por medo de necessidade imediata, alteração do número de refeições e cardápios sazonais (preparações diferenciadas, clima), fatores estes, agravantes ao desperdício de alimentos.

O planejamento dos volumes adequados deve ser realizado por um profissional qualificado, com capacidade para prever o rendimento final de cada alimento, considerando, as preparações mais consumidas e o per capita de cada alimento (ABREU et al., 2003).

Com o ajuste das preparações pode-se observar resultados positivos nos seis pólos pesquisados. A média geral de redução das sobras pode ser visualizada na figura 1.

Figura 1 - Média geral de sobras das preparações antes e após intervenções em uma unidade fornecedora de refeições transportadas, Chapecó - Santa Catarina

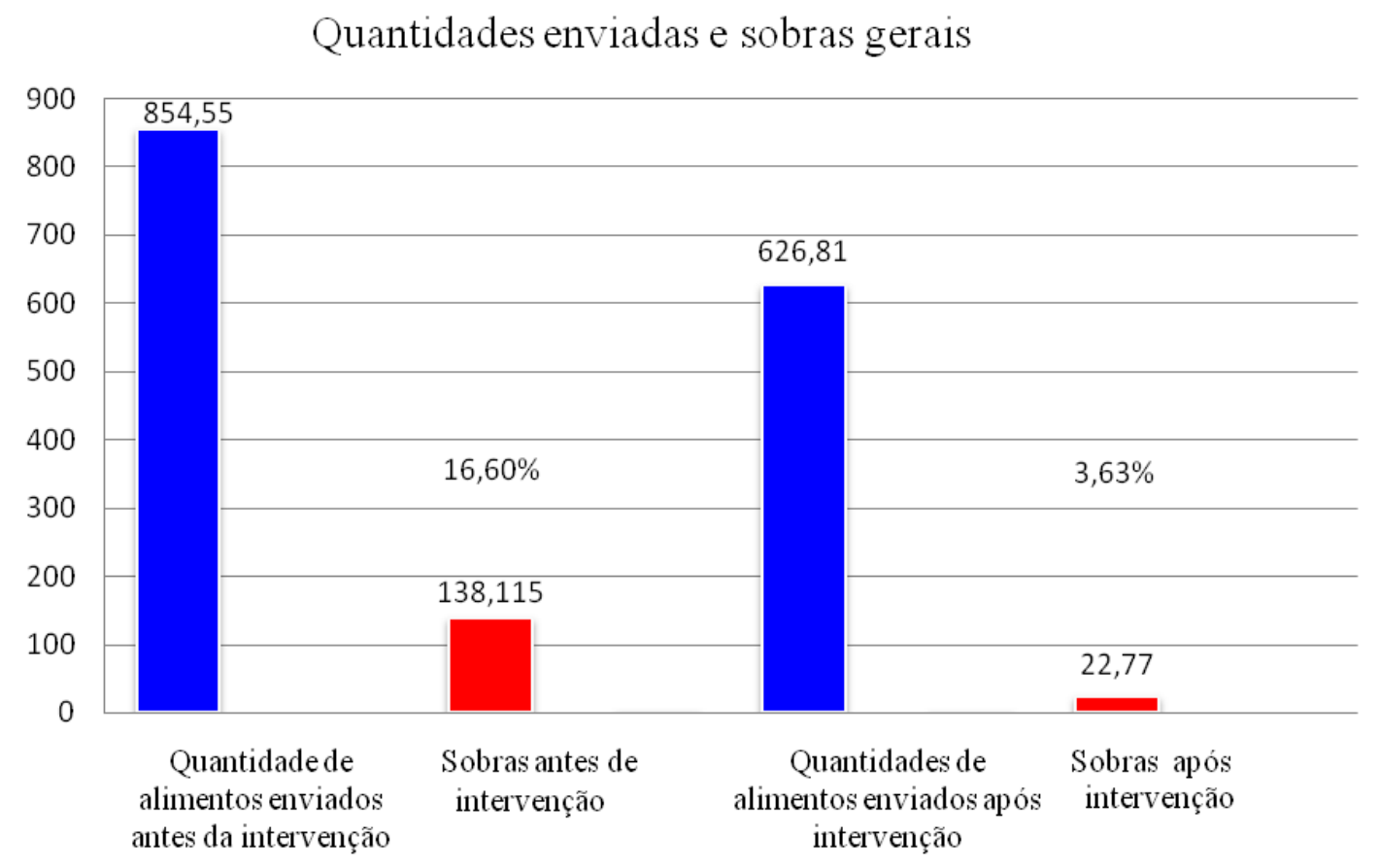

A quantidade de sobras antes das intervenções era 138,11 kg das quantidades enviadas, após ajuste e intervenções os valores de sobras baixaram para 22,77 kg da quantidade enviada.

Estudo realizado com Moura, Horaiser e Bolognini (2009) demonstra que a média de sobras de alimentos foi de $31,21 \mathrm{Kg}$. 
Pedro e Claro (2010) em um estudo de caso de um restaurante popular localizado no município de São Vicente - Estado de São Paulo, observaram um elevado desperdício de alimentos e concluíram que atingir melhorias é fundamental para a sobrevivência desses modelos de restaurante e para isso é necessário o envolvimento de toda a equipe, em todos os processos operacionais.

Os resultados apresentaram valores positivos quando comparados com os iniciais, porém sabe-se que há resistência por parte dos pólos em aceitar as cubas vazias no final da distribuição, o "medo de faltar" faz com que muitas vezes eles desconsiderem os valores de sobra. Para isso a visita técnica apresenta-se de extremamente necessária, já que assim, conseguiu-se visualizar as particularidades de cada local e reduzir ainda mais as quantidades de sobras.

Parisenti, Firmino e Gomes (2008) relatam que a qualidade da matéria-prima, variedade do cardápio, apresentação e utensílios utilizados para servir às refeições influenciam diretamente na diminuição das sobras de alimentos.

O ajuste das quantidades enviadas foi favorável a unidade estudada, pois através deles tornou-se possível saber exatamente quanto deve ser produzido, evitando assim aumento de custos e desperdício de alimentos. Entretanto esses resultados, só foram possíveis devido ao comprometimento da equipe envolvida.

Segundo Maciel (1997) o treinamento aos funcionários são de suma importância para o desempenho de qualquer tarefa, pois de modo geral, os manipuladores, ao serem admitidos não possuem qualquer treinamento na área de alimentação e nutrição.

Para Andreotti et al. (2003) é indiscutível que os programas de treinamento específicos para manipuladores de alimentos são o meio mais recomendável e eficaz para transmitir conhecimentos e promover mudanças de atitudes.

Diante dos achados percebe-se que os colaboradores compreenderam a importância da pesagem correta das cubas, assim como os responsáveis dos pólos, quanto ao envio do memorando com as quantidades de sobras através da redução de sobras.

\section{Conclusão}

Após a análise dos dados obtidos concluiu-se que a padronização dos processos de serviços, orientação a equipe e o monitoramento constante das atividades desenvolvidas, tornaram possível a diminuição das sobras nos seis pólos receptores de refeições transportadas estudados.

A diminuição das sobras traz benefícios significativos, pois reduz a produção de lixo orgânico, aumenta a lucratividade da empresa e traz maior satisfação ao empresário que obteve uma 
economia. Além disso, os comensais recebem uma alimentação de melhor qualidade através de matéria-prima selecionada e cardápios variados e de sua preferência.

\begin{abstract}
One of the basic conditions for the proper performance of the Units of Food and Nutrition is the proper planning of the volume of meals prepared, for this among other things aims to reduce or control excess production and consequent leftovers. This study aimed to analyze and control the dirty leftovers of food in a company that provides meals transported in Chapeco - SC. The study was conducted at six centers who receive meals transported. To get the value of leftover dirt were heavy tubs with the preparations sent to local as well as the remains of the Hot Box and leftover buffet. The results were positive, since the beginning of work on average $16.6 \%$ of the quantities were sent remains dirty, the final adjustment of quantities shipped, the dirty leftovers were 3.63\%. The amounts have been adjusted gradually, through contact with the poles, guidance as to the cooks portioning, as well as weekly visits to the poles identifying the particularities of each site. It was found that the standardization of procedures for the services, guidance staff and constant monitoring of the activities made possible the reduction of six poles in the dirty leftovers of meals transported receptors studied.
\end{abstract}

Key-words: food service; food collective; meals transported; food waste; inservice training

\title{
Referências
}

ABREU, E. S.; SPINELLI, M. G. N.; ZANARDI, A. M. P. Gestão de Unidades de Alimentação e Nutrição: um modo de fazer. São Paulo: Editora Metha; 2003.

ANDREOTTI, A.; BALERONI,F. H.; PAROSCHI, V. H. B.; PANZA, S. G. A. Importância do treinamento para manipuladores de alimentos em relação a higiene pessoal. Iniciação Científica, v. 5, n. 1, p. 29-33, 2003.

AMORIM, M. M. A.; JUNQUEIRA, R. G. Adequação nutricional do almoço self-service de uma empresa de Santa Luzia, MG. Revista de Nutrição, v. 18, n. 1, p. 145-156, 2005. http://dx.doi.org/10.1590/S1415-52732005000100013

CASTRO, M. D. A. S, OLIVEIRA, L. F. ; PASSAMANI, L. Resto-Ingesta e aceitação de refeições em uma Unidade de Alimentação e Nutrição. Revista Higiene e Alimentar, São Paulo, v. 17, n. 114-115, p. 24-29, 2003.

COTRIM, João; SACCOMANI, Vinícius. 2008. Para onde vão as sobras. Disponível em: <www.facasper.com.br〉. Acesso em: 13 mai 2009.

INSTITUTO ETHOS DE EMPRESAS E RESPONSABILIDADE <http://www.ethos.org.br>. Acesso em: 02 nov 2011.

KAWASAKI, V. M.; CYRILLO, D. C.; MACHADO, F. M. S. Custo-efetividade da produção de refeições coletivas sob o aspecto higiênico-sanitário em sistemas cook-chill e tradicional. Revista de Nutrição, v. 20, n. $2,2007$. http://dx.doi.org/10.1590/S1415-52732007000200002

MACIEL, G. C. Treinamento: um desafio para o nutricionista. Revista Higiene Alimentar, v. 11, n. 51, p. 7-8, 1997.

MOURA, P. N.; HONAISER, A.; BOLOGNINI, M. C. M. Avaliação do índice de resto-ingestão e sobras em unidades de alimentação e nutrição (UAN) do colégio agrícola de Guarapuava (PR). Revista Sallus - Guarapuava (PR). v. 3, n. 1, p. 15-22, 2009.

PARISIENTI, J.; FIRMINO, C. C.; GOMES, C. E. Avaliação de sobras de alimentos em unidades produtoras de refeições hospitalares e efeitos da implantação do sistema de hotelaria. Alimentos e Nutrição, v. 19, n. 2, p. 191-194, 2008.

PEDRO, M. M. R.; CLARO, J. A. C. S. Gestão de perdas em unidade de restaurante popular: um estudo de caso em são vicente. Qualit@s Revista Eletrônica, v. 9, n. 1, 2010. 
SANTOS, J. M. P.; LANZILlOTTI, H. S. Aplicação de modelo sistema Toyota de produção em unidades de alimentação. Universidade Federal de Viçosa. Ceres: Nutrição e Saúde, v. 3, n. 01, p. 09-18, 2008.

SILVA JUNIOR, E.; TEIXEIRA, R. P. A. Manual de procedimentos para utilização de sobras alimentares. 2008.

Disponível em: 〈www.sescsp.org.br〉. Acesso em: 10 de jun 2009.

TEIXEIRA, S. M. F. G.; OLIVEIRA, Z. M. C.; REGO, J. C. ; BISCONTINI, T. M. B. Administração aplicada às unidades de alimentação e nutrição. São Paulo: Atheneu, 2004. 219 p.

VAZ, C.S. Restaurantes: controlando custos e aumentando os lucros. Brasília, 2006.

Submetido em 18 mai. 2011; Revisão submetida pelos autores em 09 dez. 2011; Aceito para publicação em 13 dez.2011. 